\title{
Comparison of the Intensity of Postoperative Pain Between Open and Laparoscopic Access of Ventral Hernioplasty with IPOM (Intraperitoneal Onlay Mesh) Technique
}

\author{
Edzevit Kadri $^{1^{*}} \quad$ Katarina Panikj $^{2} \quad$ Dragoslav Mladenovic $^{3} \quad$ Gjorgji Jota $^{4} \quad$ Jasminka Nanceva $^{5}$ \\ Svetozar Antovic ${ }^{4} \quad$ Evgenija Lazova $^{1}$ \\ 1.City General Hospital 8 of September, NN Bledski dogovor 1000 Skopje, Republic of North Macedonia \\ 2.Public General Hospital Kochani, 21 Milan Zechar, 2300 Kochani, Republic of North Macedonia \\ 3.PHI University Clinic for Surgical Diseases St. Naum Ohridski, Boulevard 11 October, 1000 Skopje, \\ Republic of North Macedonia \\ 4.University Clinic for Digestive Surgery, 17 Mother Teresa, 1000 Skopje, Republic of North Macedonia \\ 5.University Clinic for Traumatology, Orthopaedic Diseases, Anaesthesia, Reanimation, Intensive Care and \\ Emergency Centre, 17 Mother Teresa, 1000 Skopje, Republic of North Macedonia
}

\begin{abstract}
Introduction: Despite the numerous advantages of laparoscopic ventral hernioplasty over the open access hernioplasty, described in the literature, the general clinical experience is that patients have severe pain in the first few days, hence early postoperative pain is a challenge in this procedure.The aim of this study was to compare early postoperative pain and whether there was statistically significant difference in the intensity of postoperative pain among patients operated with open and laparoscopic approach with IPOM hernioplasty during resting and activity.Material and methods: A randomized, prospective, comparative study was performed on 63 patients who met the inclusion criteria, operated with the IPOM technique and divided into two groups: open access in 32 patients and laparoscopic approach in 31 patients. In both groups, postoperative pain was compared at eight time intervals during rest and activity, quantified using VAS. The statistical processing and analysis of the data was done in the statistical programme SPSS version 23.0.Results: The results of the study showed that at rest and activity, patients in both groups had significantly different pain intensities on the day of the intervention, the first and second day after the intervention $(\mathrm{p}<0.0001)$. At these time points, the intensity of pain was significantly stronger in patients undergoing laparosopic hernioplasty. On the third and seventh postoperative days, as well as one and six months after the intervention, there was no significant difference in pain intensity between the two methods during rest and activity.Discussion: The general clinical experience confirmed in our study is that patients after laparoscopic ventral hernioplasty suffer from severe pain in the early postoperative period and it is the biggest challenge and problem after these operations. The explanation is that it is the result of transfascial sutures for mesh fixation in both groups and additionally multiple lesions of the parietal peritoneum in the laparoscopic method due to the numerous fixations of the mesh with tackers. Future research should focus on developing new non-traumatic methods for mesh fixation (Fibrin Glue) and studies that will analyse in detail the impact of postoperative pain on quality of life.
\end{abstract}

Keywords: Laparoscopic IPOM technique, open IPOM technique, absorbable tackers, transfascial sutures, postoperative pain.

DOI: $10.7176 / \mathrm{JHMN} / 80-08$

Publication date:September $30^{\text {th }} 2020$

\section{Introduction}

The incidence of ventral hernias worldwide is estimated at about 25 million patients annualy ${ }^{1}$, and operations on different types of ventral hernias account for $10-15 \%$ in general and abdominal surgery, hence the interest in comparing techniques of ventral hernioplasty. Laparoscopic approach for ventral hernia repair after its introduction in 1993 (KA LeBlanc), has become quite popular, due to its minimal invasiveness and also there are numerous studies that highlight its advantages over open access, such as lower rates of early postoperative complications (surgical site infections, seroma, hematoma), better cosmetic effect, shorter hospital stay ${ }^{2,3}$. Having in mind this fact, i.e. the numerous advantages of laparoscopic hernioplasty over the open access, the focus of numerous studies is aimed at researching postoperative pain which is unfortunately unacceptably high. Although laparoscopic surgery is generally considered as less painful because it is minimally invasive compared to the appropriate open access surgical method, this is not the case with ventral hernia repair. Three randomized controlled trials comparing open with laparoscopic ventral hernioplasty, showed no difference in acute or chronic pain in both procedures ${ }^{4-6}$. In fact, the general clinical experience is that patients after laparoscopic ventral hernioplasty experience severe pain, hence postoperative pain is a challenge and problem in these surgical interventions.

Pain is defined as "an uncomfortable sensory and emotional experience associated with actual or potential 
tissue damage" ${ }^{7}$. When pain is measured in clinical circumstances, it is important to know that it is complex and is the result of an individual's subjective sensation combined with emotional and cultural experience. VAS (Visual Analogue Scale) is a simple and frequently used method for quantifying the intensity of pain, which is quite effective in everyday clinical practice ${ }^{8}$. Given that this study compares postoperative pain in laparoscopic and open access ventral hernioplasty and in order to avoid the impact of the manner of mesh placement as influencing factor to the results, in both approaches the IPOM technique (intraperitoneal "onlay" mesh) was used.

\section{Objectives of the Study}

The aim of this comparative study is to compare whether there is a statistically significant difference in the intensity of early postoperative pain among patients operated with open and laparoscopic hernioplasty with IPOM technique during resting and activity.

\section{Materials and Methods}

\subsection{Study design}

This study is a randomized, prospective, comparative study conducted at the CGH "8th September " - Skopje, in the period from March 2017 to December 2019.

The study included 63 patients treated at the Department of Digestive Surgery. Patients were divided by prior randomization into two groups: 32 patients in Group 1 or patients operated with open IPOM technique and 31 patients in Group 2 or patients operated with laparoscopic IPOM technique. All patients were preoperatively informed about the surgical method and intraperitoneal placement of the mesh, the differences between the open and laparoscopic method of placement, the method of randomization, and they signed an informed consent to participate in the study. Patients were randomized by a computer programme on the day of the preoperative examination and appointment of surgery. All patients included in this study fulfil the inclusion criteria: age over 18 years, uncomplicated hernias, ASA classification I-III, defect size 3 to $10 \mathrm{~cm}, \mathrm{BMI} \leq 40$, signed informational consent. In terms of the type of hernias, patients with primary (epigastric, umbilical, Spiegel) and incisional ventral hernias (classified according to EHS - European Association of Hernias) are included. During treatment, patients adhere to the modalities of treatment included and elaborated in the EuraHS Protocols - the European Register of Abdominal Wall Hernias, the Ventral Hernia Working Group's (VHWG) assessment scale and the protocols for performing safe surgery according to the recommendations of the Ministry of Health.

For the comparison of pain in both groups, the VAS scale (Visual Analogue Scale) was used for subjective quantitative gradation of pain intensity, on a scale of $0-10$, where 0 means "no pain", and 10 indicates "high, unbearable pain". The pain in both groups was compared at eight different time points- before the intervention, on the day of the surgery 6 hours after the end of the intervention, the first, second, third, seventh, thirtieth day and six months after the intervention. The degree of pain was compared during both rest and activity, due to the impact of pain on patients' daily activities. During the hospital stay for analgesia patients were administered Amp.Ketoprofen 2x100 mg and Amp.Tramadol 3x100 mg alternately, while at home it was recommended to take Tbl.Ibuprofen 400mg 2x1 and Tbl.Paracetamol 500mg as needed. The information about the degree of pain during the hospital stay was obtained personally from the patients, and after the discharge from hospital, the information was obtained through a telephone conversation with the patient.

\subsection{Surgical procedure}

All patients were operated under general anaesthesia and in all patients polypropylene composite mesh Parietene with absorbent synthetic film (of various sizes) was used. In both groups, the mesh is placed intraperitoneally - IPOM technique (intraperitoneal onlay mesh), fixed with non-absorbent transfascial sutures (Prolene 0 ) and additionally with absorbable tackers in the laparoscopic group.

The open access surgical technique includes: incision at the site of the previous scar or hernia defect, adhesiolysis, measurement of the defect and plan for mesh placement, intraperitoneal placement of the mesh and fixation with transfacial sutures (on average 8 sutures) with overlap of $3-5 \mathrm{~cm}$ depending on the size of the defect, closing the defect (if possible), drainage in certain cases. ${ }^{9,10}$

The surgical technique for laparoscopic approach includes: pneumoperitoneum - by open method or with a Veress needle, placing working troacar as far away from the defect as possible, adhesiolysis, measuring the defect and placing the mesh intraperitoneally and fixation of the mesh with the transfascial sutures and absorbable tackers ("Double -Crown") at a distance of about $1.5-2.5 \mathrm{~cm} .{ }^{11,12}$

\subsection{Statistical analysis}

Statistical processing and data analysis was performed in the statistical program SPSS for Windows 23.0. Kolmogorov-Smirnov and Shapiro Wilk's test were used to test the normality in data distribution. Quantitative traits are represented by an arithmetic mean with a standard deviation and a median mean, and qualitative traits are represented by absolute and relative numbers. Bivarian analysis was performed to compare the analysed 
groups (laparoscopic and openhernioplasty). Pearson Chi-square test was used to compare the two groups in terms of quality marks, Student t-test and Mann-Whitnney test were used to compare these groups in terms of quantitative marks. The values of $\mathrm{p}<0.05$ were taken as statistically significant.

\section{Results}

Table 1 presents the socio-demographic and clinical characteristics of respondents, patients with laparoscopic and open hernioplasty of ventral hernias. Both groups of respondents were homogenous in terms of their gender and age $(p=0.38, p=0.73)$, respectively. There was no gender difference between the two groups, although female patients were the majority of respondents in both groups-58.1\% vs $68.75 \%$. The mean age was similar in patients with laparoscopic and classical intervention (53.64 $\pm 13.7 \mathrm{vs} 54.65 \pm 9.5)$.

Primary ventral hernia was diagnosed insignificantly frequent in patients undergoing laparoscopic hernioplasty- $41.9 \%$ vs $28.1 \%$.

Patients with ASA score of 2- 64.5\% and 53.1\%, respectively, were most commonly included in the study.

The size of the fascial defect was insignificantly different between patients with laparoscopic and open hernioplasty $(\mathrm{p}=0.09)$. The average size of the fascial defect in the laparoscopic and open technique was 32 and $35 \mathrm{~cm}^{2}$, respectively.

Table 1. Characteristics of the respondents

\begin{tabular}{|c|c|c|c|}
\hline \multirow[t]{2}{*}{ Variable } & \multicolumn{2}{|c|}{ Hernioplasty } & \multirow[t]{2}{*}{ p value } \\
\hline & Laparoscopic & Open & \\
\hline \multicolumn{4}{|l|}{ Gender $n(\%)$} \\
\hline Male & $13(41.94)$ & $10(31.25)$ & \multirow{2}{*}{$\chi^{2}=0.78 \mathrm{p}=0.38 \mathrm{~ns}$} \\
\hline Female & $18(58.06)$ & $22(68.75)$ & \\
\hline \multicolumn{4}{|l|}{ Age } \\
\hline$($ mean $\pm \mathrm{SD})$ & $53.64 \pm 13.7$ & $54.65 \pm 9.5$ & $\mathrm{t}=0.34 \mathrm{p}=0.73 \mathrm{~ns}$ \\
\hline \multicolumn{4}{|l|}{ BMI } \\
\hline$($ mean $\pm \mathrm{SD})$ & $29.05 \pm 4.2$ & $28.99 \pm 3.4$ & $\mathrm{t}=0.06 \mathrm{p}=0.95 \mathrm{~ns}$ \\
\hline \multicolumn{4}{|c|}{ Type of hernia n(\%) } \\
\hline Primary & $13(41.94)$ & $9(28.13)$ & \multirow[t]{2}{*}{$\chi^{2}=1.32 \mathrm{p}=0.25 \mathrm{~ns}$} \\
\hline Incisional & $18(58.06)$ & $23(71.88)$ & \\
\hline \multicolumn{4}{|c|}{ Size of fascial defect $/ \mathrm{cm} 2$} \\
\hline$($ mean $\pm \mathrm{SD})$ & $(33.67 \pm 11.9)$ & $(35.55 \pm 19.4)$ & \multirow[t]{2}{*}{$\mathrm{Z}=1.63 \mathrm{p}=0.09 \mathrm{~ns}$} \\
\hline median (IQR) & $32(12-30)$ & $35(18-48)$ & \\
\hline \multicolumn{4}{|c|}{ ASA classification $n(\%)$} \\
\hline 1 & $5(16.13)$ & $6(18.75)$ & \multirow[t]{3}{*}{$\chi^{2}=0.92 \mathrm{p}=0.63 \mathrm{~ns}$} \\
\hline 2 & $20(64.52)$ & $17(53.13)$ & \\
\hline 3 & $6(19.35)$ & $9(28.13)$ & \\
\hline
\end{tabular}

$\chi^{2}$ (Chi-square test); $\mathrm{t}$ (Student t-test); Z (Mann-Whitney test)

We compared patients with laparoscopic and open hernioplasty in terms of subjective perception of pain intensity, quantified by VAS scale, at 8 time points (before surgery, on the day of intervention, first, second, third, seventh, thirtieth day and six months after the intervention), during rest and activity.

According to the results in Table 2, at rest, patients in both groups had significantly different pain intensities on the day of intervention, the first and second day after the intervention $(\mathrm{p}<0.0001)$. At all these time points, the pain intensity was significantly higher in patients undergoing laparoscopic hernioplasty, with a mean VAS score of 7 and 5, consequently, immediately after the intervention; 6 and 4, consequently, the first day after the intervention; 5 and 3, consequently, the second day after the intervention. On the third and seventh day after intervention, patients in both groups had an identical mean VAS score for pain intensity (median $3 ; p=0.15$, median $2 ; \mathrm{p}=0.16)$. At rest, more than half of the patients in both groups had no pain after one month of intervention, while at the end of 6 months follow-up after the intervention, no patient felt pain. 
Table 2. VAS scale at rest- laparoscopic and open hernioplasty

\begin{tabular}{|c|c|c|c|}
\hline \multirow[t]{2}{*}{ VAS/ resting } & \multicolumn{2}{|c|}{ Hernioplasty } & \multirow[t]{2}{*}{ p value } \\
\hline & Laparoscopic & Open & \\
\hline \multicolumn{4}{|l|}{ Preoperative } \\
\hline$($ mean $\pm \mathrm{SD})$ median (IQR) & $(0.29 \pm 0.6) \quad 0(0-0)$ & $(0.03 \pm 0.2) \quad 0(0-0)$ & $\mathrm{Z}=1.3 \mathrm{p}=0.18 \mathrm{~ns}$ \\
\hline \multicolumn{4}{|l|}{ On the day of surgery } \\
\hline$($ mean $\pm \mathrm{SD})$ median (IQR) & $(6.77 \pm 0.6) 7(6-7)$ & $(5.16 \pm 0.7) 5(5-6)$ & $\mathrm{Z}=6.1 \mathrm{p}=0.000 \mathrm{sig}$ \\
\hline \multicolumn{4}{|l|}{ I day postoperative } \\
\hline$($ mean $\pm \mathrm{SD})$ median $(\mathrm{IQR})$ & $(5.77 \pm 0.7) \quad 6(5-6)$ & $(4.16 \pm 0.7) 4(4-5)$ & $\mathrm{Z}=5.9 \mathrm{p}=0.000 \mathrm{sig}$ \\
\hline \multicolumn{4}{|l|}{ II day postoperative } \\
\hline$($ mean $\pm \mathrm{SD})$ median (IQR) & $(4.55 \pm 0.7) 5(4-5)$ & $(3.41 \pm 0.7) \quad 3(3-4)$ & $\mathrm{Z}=4.9 \mathrm{p}=0.000 \mathrm{sig}$ \\
\hline \multicolumn{4}{|l|}{ III day postoperative } \\
\hline$($ mean $\pm \mathrm{SD})$ median $(\mathrm{IQR})$ & $(3.42 \pm 0.9) \quad 3(3-4)$ & $(3.37 \pm 0.5) \quad 3(2-3)$ & $\mathrm{Z}=1.37 \mathrm{p}=0.15 \mathrm{~ns}$ \\
\hline \multicolumn{4}{|l|}{ VII day postoperative } \\
\hline$($ mean \pm SD) median $(\mathrm{IQR})$ & $(1.93 \pm 0.7) 2(2-2)$ & $(1.66 \pm 0.5) \quad 2(1-2)$ & $\mathrm{Z}=1.4 \mathrm{p}=0.16 \mathrm{~ns}$ \\
\hline \multicolumn{4}{|l|}{ One month postoperative } \\
\hline$($ mean $\pm \mathrm{SD})$ median $(\mathrm{IQR})$ & $(0.48 \pm 0.6) \quad 0(0-1)$ & $(0.28 \pm 0.5) \quad 0(0-1)$ & $\mathrm{Z}=1.2 \mathrm{p}=0.22 \mathrm{~ns}$ \\
\hline \multicolumn{4}{|l|}{ Six months postoperative } \\
\hline$($ mean $\pm \mathrm{SD})$ median $(\mathrm{IQR})$ & 0 & 0 & \\
\hline
\end{tabular}

Z (Mann-Whitney test)

The results of distribution of VAS scores at rest showed that on the day of the intervention more than half of the patients from the laparoscopic group, respectively $58.1 \%$ rated the pain with a score of 7 , while in the group of patients operated with open hernioplasty, the majority of patients rated the pain with a score $5(46.9 \%)$. A higher percentage of patients treated laparoscopically evaluated the pain with higher intensity the first, second, third, seventh day and 30 days postoperatively, but without statistical significance the third, seventh and thirty days after the intervention. One month postoperatively, the highest score was 2 , assigned by $3.3 \%$ of patients with laparoscopic hernioplasty and none of the group with open hernioplasty.

In the state of activity, on the day of the intervention and two days later, the results presented a significantly different intensity of pain depending on type of hernioplasty $(p<0.0001)$. Patients with laparoscopic surgery had significantly higher pain than patients with open hernioplasty and rated the intensity with an average score of 8 vs 6 on the day of intervention; 7 vs 6 first postoperative day; 6 vs 5 second postoperative day.

On the third and seventh postoperative days, no significant difference was observed in the intensity of pain between the two groups of patients (mean score was $5 ; \mathrm{p}=0.22$ and 3 in both groups; $\mathrm{p}=0.16$, respectively). The difference was insignificant one and six months after the intervention $(\mathrm{p}=0.19, \mathrm{p}=0.25$, consequently). In the active state, 30 days postoperatively in both groups the lowest mean score for pain intensity $($ median $=1)$ was recorded, while 6 months postoperatively, more than half of the patients in both groups had no pain (Table 3).

Table 3. VAS scale during activity- laparoscopic and open hernioplasty

\begin{tabular}{|c|c|c|c|}
\hline \multirow[t]{2}{*}{ VAS / during activity } & \multicolumn{2}{|c|}{ Hernioplasty } & \multirow[t]{2}{*}{ p value } \\
\hline & Laparoscopic & Open & \\
\hline \multicolumn{4}{|l|}{ Preoperative } \\
\hline$($ mean $\pm \mathrm{SD})$ median (IQR) & $(1.32 \pm 0.9) \quad 1(1-2)$ & $(1.0 \pm 0.8) \quad 1(0-1.5)$ & $\mathrm{Z}=1.1 \mathrm{p}=0.26 \mathrm{~ns}$ \\
\hline \multicolumn{4}{|l|}{ On the day of surgery } \\
\hline$($ mean $\pm \mathrm{SD})$ median (IQR) & $(8.32 \pm 0.6) \quad 8(8-9)$ & $(6.34 \pm 0.8) \quad 6(6-7)$ & $\mathrm{Z}=6.4 \mathrm{p}=0.000 \mathrm{sig}$ \\
\hline \multicolumn{4}{|l|}{ I day postoperative } \\
\hline$($ mean $\pm \mathrm{SD})$ median $(\mathrm{IQR})$ & $(7.45 \pm 0.7) \quad 7(7-8)$ & $(5.78 \pm 0.8) 6(5-6)$ & $\mathrm{Z}=5.8 \mathrm{p}=0.000 \mathrm{sig}$ \\
\hline \multicolumn{4}{|l|}{ II day postoperative } \\
\hline$($ mean $\pm \mathrm{SD})$ median $(\mathrm{IQR})$ & $(6.09 \pm 0.9) \quad 6(5-7)$ & $(4.91 \pm 0.7) 5(4-5)$ & $\mathrm{Z}=4.4 \mathrm{p}=0.000 \mathrm{sig}$ \\
\hline \multicolumn{4}{|l|}{ III day postoperative } \\
\hline$($ mean $\pm \mathrm{SD})$ median (IQR) & $(4.68 \pm 0.9) 5(4-5)$ & $(4.81 \pm 0.7) 5(3-5)$ & $\mathrm{Z}=1.12 \mathrm{p}=0.22 \mathrm{~ns}$ \\
\hline \multicolumn{4}{|l|}{ VII day postoperative } \\
\hline$($ mean $\pm \mathrm{SD})$ median $(\mathrm{IQR})$ & $(3.39 \pm 0.9) \quad 3(3-4)$ & $(3.06 \pm 0.7) 3(3-3.5)$ & $\mathrm{Z}=1.4 \mathrm{p}=0.16 \mathrm{~ns}$ \\
\hline \multicolumn{4}{|l|}{ One month postoperative } \\
\hline$($ mean $\pm \mathrm{SD})$ median $(\mathrm{IQR})$ & $(1.48 \pm 0.7) \quad 1(1-2)$ & $(1.25 \pm 0.7) \quad 1(1-2)$ & $\mathrm{Z}=1.3 \mathrm{p}=0.19 \mathrm{~ns}$ \\
\hline \multicolumn{4}{|l|}{ Six months postoperative } \\
\hline$($ mean $\pm \mathrm{SD})$ median $(\mathrm{IQR})$ & $(0.39 \pm 0.5) \quad 0(0-1)$ & $(0.22 \pm 0.4) \quad 0(0-0)$ & $\mathrm{Z}=1.1 \quad \mathrm{p}=0.25 \mathrm{~ns}$ \\
\hline
\end{tabular}


According to the distribution of scores from the VAS scale during activity, in the whole period of follow-up a large percentage of patients treated laparoscopically assessed the pain with higher intensity, but statistical significance was registered until the third day postoperatively (Table 3 ).

On the day of the intervention, the highest percentage of patients in the laparoscopic group rated the pain with a score of $9(54.8 \%)$, while in the group of patients with open hernioplasty, $50 \%$ of patients rated the pain with a score of 6 . The sixth month postoperatively, the highest score was 1 , assigned by $38.3 \%$ patients with laparoscopic hernioplasty and $21.9 \%$ patients from the open hernioplasty group.

\section{Discussion}

The results of our study show that there is a significant difference in postoperative pain in the early stage and it is more intense in laparoscopic than in open IPOM technique on the day of surgery, the first and second postoperative day at rest and during activity, while on the third and seventh day, as well as after one and six months postoperatively, there is no significant difference in pain intensity between the two methods.

These differences in pain intensity in the early postoperative period arise from the way of mesh fixation. Transfascial sutures used for fixation in both methods, penetrate the entire thickness of the abdominal wall, including fascia, musculature, subcutaneous tissue and skin. They provide solid fixation due to higher tensile forces and there are studies that confirmed that transfascial sutures are associated with a lower recurrence rate ${ }^{13,14}$. However, when tranasfascial sutures are placed, damaged nerves and blood vessels can be "trapped" which in turn leads to tissue ischemia, necrosis and pain. Today, there is sufficient evidence to suggest that the use of transfascial sutures results in significant postoperative pain ${ }^{15,16,17}$. Additionally, in our case, mesh fixation in laparoscopic method is enhanced by absorbable tackers. During fixation, tackers penetrate the abdominal wall and also contribute to local tissue damage. Hence, we can assume that the greater intensity of pain in the first days of laparoscopic approach is due to the cumulative effect of two mesh fixation techniques, on the one hand transfascial sutures and on the other hand multiple lesions caused from the tackers on parietal peritoneum. The parietal peritoneum is an organ strongly innervated by somatic and visceral afferent nerves sensitive to pain, pressure, friction, cutting and temperature ${ }^{18}$, hence that is the logical conclusion for greater pain in laparoscopic approach hernioplasty.

The general clinical experience confirmed in our study is that the patients after laparoscopic ventral hernioplasty, in the early postoperative period suffer from severe pain and it is the biggest challenge and problem after these operations. Therefore, the use of adapted analgesia in patient with laparoscopic approach is imposed as a conclusion for the daily clinical practice.

This is one of the few comparative studies of the two approaches to the IPOM technique. The first comparative study comparing long-term results with the IPOM technique was published in 2019. In that study, as in ours, in order to eliminate the influence of the position of the mesh on the results, in both groups (laparoscopic and open) the mesh is placed intraperitoneally.

Unfortunately, there is still a lack of detailed studies describing pain and its impact on reconvalescents and quality of life after laparoscopic ventral hernioplasty in the available literature. Future research should focus on developing new atraumatic fixation methods. For now, the use of cyanoacrylate glue for mesh fixation gives optimistic results given the initial reports describing good integration in the abdominal wall and a small inflammatory response, but serious research is still needed before widespread use begins ${ }^{20,21}$.

\section{References}

1. MR Langenbach, D. Enz (2020). Mesh fixation in open IPOM procedure with tackers or sutures? A randomized clinical trial with preliminary results. Hernia, The World Journal of Hernia and Abdominal Wall Surgery. 24(1):79-84.

2. Forbes SS, Eskicioglu C, McLeod RS et al.(2009) Meta-analysis of randomized controlled triales comparing open and laparoscopic ventral and incisional hernia repair with mesh. Br J Surg. 96:851-8.

3. McGreevy JM, Goodney PP, Birkmeyer CM, Finlayson SRG, Laycock WS, Birkmeyer JD. (2003) A prospective study comparing the complication rates between laparoscopic and open ventral hernia repairs. Surg. Endosc. 17:1778-1780.

4. Merskey H (Eds.) and International Association for the Study of Pain Subcommittee on Taxonomy. (1986) Classification of chronic pain syndromes and definitions of pain terms. Pain Suppl. 3: S1-226.

5. Scott, J. and Huskisson, E.C. (1976) Graphic representation of pain. Pain, (2nd ed.). 175-184.

6. Misra MC, Bansal VK, Kulkarni MP et al.(2006). Comparison of laparoscopic and open repair of incisional and primary ventral hernia: results of a prospective randomized study. SurgEndosc. 20: 1839-45.

7. Barbaros U, Asoglu O, Seven R et al.(2007). The comparison of laparoscopic and open ventral hernia repairs: a prospective randomized study. Hernia. 11:51-6

8. Asencio F, Agulió J, Peiró S et al. (2009). Open randomized clinical trial of laparoscopic versus open incisional hernia repair. SurgEndosc. 23: 1441-8. 
9. Jones, Daniel B. (2012) Master Techniques in Surgery: Hernia. (1st ed). Lippincott Williams \& Wilkins (LWW), p.245-385.

10. Köckerling F and Lammers B (2018): Open Intraperitoneal Onlay Mesh (IPOM) Technique for Incisional Hernia Repair. Front. Surg. 5:66. doi: 10.3389/fsurg.2018.00066

11. Karl A. LeBlanc, MD. (2000). Current Considerations in Laparoscopic Incisional and Ventral Herniorrhaphy. JSLS. 4(2): 131-139

12. Mohamed WBA et al. (2017). Laparoscopic versus open incisional hernia repair: comparative nonrandomized study. IntSurg J. 4(7):2216-2220

13. Eid GM, Prince JM, Mattar SG, Hamad G, Ikrammudin SI, Schauer PR.(2003). Medium-term follow-up confirms the safety and durability of laparoscopic ventral hernia repair with PTFE. Surgery. 143:599-604.

14. Carbajo MA, Martin delOlmo JC, Blanco JI et al. (2003). Laparoscopic approach to incisional hernia. Lessons learned from 270 patients over 8 years. Surg. Endosc. 17:118-122.

15. Wassenar E, Schoenmaeckers E, Raymakers J, et al.(2010) Mesh-fixation method and pain and quality of life after laparoscopic ventral or incisional hernia repair: a randomized trial of three fixation techniques. Surgendosc. 24(6):1.296-302.

16. Muysoms F, Vander Mijnsbrugge G, Pletinckx P, et al. (2013). Randomized clinical trial of mesh fixation with "double crown" versus "sutures and tackers" in laparoscopic ventral hernia repair. Hernia. 17(5): 60312.

17. Carbonell AM, Harold KL, Mahmutovic AJ, et al.(2003). Local injection for the treatment of suture site pain after laparoscopic ventral hernia repair. The American Surgeon. 69(8):688-91; discussion 691-2.

18. Struller et al.,(2017) Peritoneal intervention: embryology et functional anatomy, Pleura and Peritoneum. 2(4): 153-161

19. Lavanchy L. J, Buff E. S, Kohler A, Candinas D, Beldi G.(2019). Long-term results of laparoscopic versus open intraperitonealonlay mesh incisional hernia repair: a propensity score-matched analysis. Surgical Endoscopy. 33:225-233.

20. Ladurner R, Drosse I, Burklein D, et al. (2011). Cyanoacrylate glue for intra-abdominal mesh fixation of polypropylene- polyvinylidene fluoride meshes in a rabbit model. J Surg Res. 167(2):e 157-62.

21. Losi P, Burchielli S, Spiller D, et al. (2010). Cyanoacrylate surgical glue as an alternative to suture threads for mesh fixation in hernia repair. J Surg Res. 163 (2):e53-8. 